\title{
The Positive Psychology of Gaming: Immersion through Flow in Simulations
}

\author{
Müberra Yüksel \\ Kadir Has University, Istanbul-Turkey
}

\begin{abstract}
Lately, online games have been gaining increasing attention as an outlet. In "positive psychology", Csikszentmihalyi (1991) found out that a large part of happiness is achieved by voluntary activities - half of which is determined by flow. Csikszentmihalyi studied people's inner states while pursuing activities that appear to contain intrinsic rewards, such as dance, sports and music. He highlighted an experience of "flow state" which is merging action and awareness through total immersion in an activity that is challenging yet closely matched to one's skills (1991). Gaming may be emancipatory due to their framing within interactive, decentralized and self-organizing platforms.

While flow is highly correlated with subjective well-being, it also enhances focus, perception, learning capacity, recall and self-esteem of players. Playing online games that are embedded in social media such as Facebook and Twitter is more than an isolated competition against a computer; it is both an interactive experience of a second self and a shared group action. Getting immediate feedback can induce high levels of engagement in the game as well as a feeling of control and development. Such games provide the highest degree of concentration simultaneously with social networking. Consequently, this new venue may enhance an optimal experience of flow along with a heightened interest in creativity, collaborative discovery and learning, if employed properly. Based on both the prior empirical research and literature, The researcher has I analyzed a few examples from commercial games of an emergent economy and then reviewed findings and inferences on serious games.
\end{abstract}

Keywords: Online games, flow, serious games and advergames.

\section{Introduction}

Nowadays, capturing attention and raising awareness on any issue demands both art and science. New media may be also used in an emancipatory rather than repressive manner through its interactive, decentralized and self-organizing platforms. Apart from threats to privacy based on either "surveillance" model of Foucault or "capture" metaphor of Agre, the future of on-line games is more promising than "rule-driven" video games that isolate people while making players lose themselves in a simulated world of experience.
Playing online games that are embedded in social media like Facebook, Twitter, is more than an individual competition against a computer as a "rational perfect mirror"; it is both an interactive experience of a second self and a shared group action. It provides highest degree of focus and concentration simultaneously with social networking. This new venue may enhance flow along with search for discovery and creativity if employed properly (Cziksenmihalyi, 1991). Online games have additional features that encourage state of flow, or optimal experiences of the positive psychology perspective. They provide rich and immediate feedback and the ability to

Copyright (C) 2012 Müberra Yüksel. This is an open access article distributed under the Creative Commons Attribution License unported 3.0, which permits unrestricted use, distribution, and reproduction in any medium, provided that original work is properly cited. Contact author: Müberra Yüksel E-mail: muberray@khas.edu.tr 
induce higher levels of immersion in the game and a feeling of control (Chiang et al., 2011).

In a search for non-traditional marketing and business communication that emphasizes pull factors instead of push factors and the growing use of the internet and mobile devices, viral marketing and advertising blogs are attracting increased attention as a potentially inexpensive way of reaching targeted groups of consumers, particularly the youth. Behavioral targeting and mood matching are to deliver messages that engage audiences and ensure content is absorbed rather than merely recalled. The most effective way to reach young audience seems to be through in-game advertising. When engaged in an online gaming session that is challenging, people prefer full engagement and concentration rather than doing simultaneous tasks like chatting. Therefore, advergaming is an effective way to communicate marketing and advertising content with people.

The need to develop new methods of internet advertising arose from the rapid decline, in the late 1990s, of the effectiveness of rich media banner advertising along with an increasing spam of on-line direct marketing (Yuan et al., 1998). Advergames have been defined as online games that incorporate marketing and communication content. They are interactive games that are centered on a brand, a product, or a character associated with a brand or a product.

Branding and products are incorporated into the game itself through either associative or demonstrative methods meaning that a game can be used to demonstrate the use of a product or to associate the product with an activity or a lifestyle. The meaning of advergames is multi-dimensional since they may be seen as a developing industry, as a new advertising system, as a viral marketing tool as well as a form of entertainment.

All of these demonstrate a huge potential of such games (Sennott, 2004). Yet, despite the publicity created by this new advertising method, most of the information debating advergames is professionally oriented (Bannan, 2002; Hartsock, 2004). Few academic studies investigated the characteristics of the advergames and their influence on consumers' perceptions and behavior (Hernandez et al., 2004; Nelson, 2002).

In this paper, the researcher will first highlight the major characteristics of effective in-game advertising with due respect to "optimal autotelic experience"that is, intrinsic reward coming from the activities involved in the games themselves. These include clear goals, immediate feedback, loss of a sense of time and selfconsciousness and an integration of the self within the activity (Cziksenmihalyi, 1991). After having identified the main features of effective advergames, the researcher will first analyze them within Turkish context. She will then discuss the two different game genres, namely advergames and serious games, and new media such as the internet, which are enabling their development as immersive platform.

\section{Literature Review and Theoretical Framework}

Studies conducted in emergent economies like Turkey have discovered that games are extremely popular among all categories of online users. The main reason for women is to relieve or eliminate stress, while men are mainly attracted by the competitive factor of Internet gaming. The women prefer word and puzzle games, while men are more interested in sports, combat or casino games (Arkadium, 2004). An empirical research (Youn et al., 2005) compares people who play games on the Internet, people who use the Internet but not for gaming, and people who do not use the Internet. On-line gamers are found to be the youngest group and have aboveaverage education and income, but nongaming Internet users enjoy the highest socioeconomic status of female adult consumers. 
In terms of motivation, on-line gamers are more impulsive and more open to the Internet than any of the other groups. Online gamers are also highest in novelty seeking, risk-taking and word-of-mouth communication. Their findings also suggest that female adult consumers are expected to be a growing market in the gaming industry and advertisers have an opportunity to reach female consumers using online games as the venue promoting their brands.

More importantly, advertisers need to direct their efforts toward designing gender-specific advergames to better accommodate female consumers (Youn et al., 2005). From a marketing point of view, these games may be used for various reasons as:

- Increasing the recognition of a company, a brand or a product;

- Associating positive emotions with a company, a brand or a product;

- Initiating an action of viral marketing;

- Introducing and facilitate a promotional campaign;

- Inducing a purchasing behavior, i.e., increasing the volume of sales.

The interaction with Internet applications can also induce the state of flow in specific circumstances (King, 2003). Mihaly Csikszentmihalyi (1991) outlines that the most successful web sites are the ones that offer interactive experiences, not simply content. The state of flow can be created online if the following essential conditions are combined: user motivation, user telepresence and interactivity of the Internet application. On the other hand, the existence and maintenance of the state of flow is a dynamic process that depends on the relation between the capabilities of the user, or player in the case of an advergame, and the level of difficulty proposed by the game.

Numerous researchers have used the Flow Model through different qualitative and quantitative methods to explore various aspects of human-online interaction (Chiang et al., 2011; Chen, 2006; Pearce, etal., 2004). The findings are not certain, since controlling for addicted players is not possible and the effect of flow experiences on positive affect is not clear. Yet, research about the flow experience on players or on distinguishing characteristics of effective advergames is few (See Cauberge, V. \& De Pelsmacker, 2010).

There are often three possible simplified scenarios of the interaction between an Internet user and an online game. When the capability of the player is lower than the level of difficulty of the advergame, the player will experience frustration and will abandon the game with a negative feeling. If the capability of the player is higher than the level of difficulty proposed by the game, a feeling of boredom is likely to result, having as a direct effect the exit of the player from the advergame environment.

Finally, if the level of capability of the player and the level of difficulty of the advergame match, the state of flow results and reinforces the motivation of the Internet user to revisit the site and to play again the game. However, the situation is more complex than that. Once induced, the maintenance of the state of flow requires a constantly evolving challenge for the player, because his/her level of capability is likely to improve after playing the game a few times. This raises the problem of including in the game a progressive level of difficulty that can represent a dynamic challenge for the players.

The psychological basis of this process is the inducement and the use of the 'state of flow'. This concept is used by psychologists to describe a mental state in which the attention is highly concentrated on a specific process, the environmental information is screened out and the person experiences a harmonious flow of its present experience (Csikszentmihalyi, 1991). The state of flow is known to create a state of well being as well as increased perception and learning capacity. 
The state of flow can be induced by any activity that is very interesting for a person: watching a movie, reading a book, or playing a game. In fact, the playing is considered one of the best inducers of the flow state for children, and often so for adults. The interaction with Internet applications can also induce the state of flow in specific circumstances (King, 2003). Bakhtin regards virtual world as a "postmodern chronotope" where a loss of the sense of passing time and loss of perception of space is simultaneous (1986).

As any other marketing communication tool, in-game advertising characteristics have to correspond to: (1) the personality of the advertised brand, (2) the profile of the targeted audience, (3) the characteristics of the medium - in this case the Internet, and (4) the strategic objectives of the communication campaign. In sum, the creation of an effective advergame is considered predominantly a creative design work, which has difficult criteria to be defined in a formal, precise manner.

Csikszentmihalyi used the experience sampling methodology (ESM) with his flow theory (See Figure 2 below) to be able to analyze the balance of experiences in the below four channels with four alternative edges leading to various combinations of skill and challenge levels. For any player to attain flow in a game or any activity, a balance needs to be achieved between the external complexity of the system or game program and the internal model a user/ player develops of that particular program. A player attains a more accurate internal model of system through learning and virtual experience by trial and error.

All sorts of games provide useful tools for generating feedback for novice game players, for experience-based learning. When constructed with different learning styles of individuals in mind, games can accelerate the learning process interactively by repeated experience and recall; the last two are especially taken into account in advergames. The four C's for well-constructed games of all kinds are:
Conflict: players must overcome obstacles to do a challenging task and achieve a goal,

Control: the game must have a clear set of rules,

- Closure: the end of the game is timebound or limited with a certain number of players.

Contrivance: making mistakes and trial and error is easy by its nature; games used to foster learning work best when competitive elements are minimized and emphasis is put on the value of the fun experience.

Competency: the specific skills to be improved by this game.

In a simplified understanding of model of flow, there are mainly six possible combinations with respect to experience sampling methodology (See Johnsson and Persson, 2006). Key variables have been defined in direct relation to six of the defined characteristics in this study: Accessibility, challenge levels with respect to rules and competitiveness, relevance, viral (word-of-mouth) marketing and the extent of flow. An objective evaluation of the advergame relevance for the company, brand and/or product advertised is difficult at this stage, because it is necessary to define a number of quantifiable criteria that can describe and assess the personality of a brand.

By and large, capturing the attention and learning through digital games seems to be the best way to reach the youth, namely "digital natives" in their own language, despite the fact that some cultures are relatively less comfortable with games that require high degrees of participation in teams or self-disclosure. 


\section{Findings in Turkey as an Emergent Economy}

In order to verify the existence of six key characteristics delineated in the profile of active online games, advergames on various web sites have been randomly browsed. First, a quick search on the Internet delineated that the ten types of products were widely using advergames internationally: Automotive and accessories, comics, travel, FMCGs (including food \& beverages and cosmetics), watches, computer \& equipment, software, entertainment and textiles. Fifteen active advergames selected with respect to sectors in Turkey had the following distribution in terms of type of products/industries represented; only five of them are widely played by Turkish youth (See the products in italics in Table 1 below). The types of products/sectors represented by the analyzed advergames are:

\begin{tabular}{|l|c|}
\hline Table 1. Type of Product & Frequency \\
\hline Automotive & 3 \\
\hline Telecommunication-GSM & 2 \\
\hline Attire & 1 \\
\hline Holidays & 1 \\
\hline Food and beverages inc. energy drinks & 5 \\
\hline Credit Cards (prepaid service card) & 1 \\
\hline Computer equipment & 1 \\
\hline Toys & 1 \\
\hline Durables & 1 \\
\hline
\end{tabular}

As shown in the above Table 1, the 'food and beverages' are the dominant of all the advergames surveyed. Automotives are also well represented, with three games, and telecommunication with two games and others with lower frequency. The analysis of the data reveals a profile of the investigated advergames of convenient sampling:

Accessibility: facility to identify the hyperlink between the firm/product site and the game, free access or required registration, specialized software required, downloading time; sufficient, as well as the facility to understand the instructions, although in a few cases the rules can be significantly simplified.

\section{$>$ Difficulty of Understanding /} Challenge One: existence of explicit instructions/rules, and the facility of understanding these rules. The competitive level of advergames can be improved, either by publishing the score lists, or by creating multi-player shared environments that are already the norm in the computer games industry.

Competitive Level/ Challenge Two: number of players, the display of score lists, multiple level of difficulty; most of them have a low level of flexibility they propose only one or two levels of difficulty, and the players are not able to choose the difficulty level they desire.

Relevance for the Company, Brand or Product: type of product advertised, type of game, advertising elements associated with the game; not easy to assess.

Viral Marketing: Communication with Friends and Family Members: The actions of viral marketing need to be developed, since all games do not provide a direct encouragement and a direct possibility for players to contact friends or family members since identification data introduced by the players about themselves or about prospective players can represent a valuable input into an online database.

Capacity to Induce and Maintain the State of Flow: multiple levels of difficulty, the possibility offered to players to choose a specific level of difficulty: it is the most difficult to assess for the state of flow is a subjective aspect, which can be identified in relation to a person's pattern of behavior, and not the game itself. 
On the whole, either an experimental research with treatment and control group of students to explore game players' flow experience as in (Asakawa, 2004; Chiang. et al, 2011) or an experiential model that Csikzenmihalyi suggested would have overcome the limitations of this exploratory inquiry is applicable in the context of Turkey. Neither the sample size nor the data size was sufficient for these two methods. Instead, by using narrative interviews of ten students of advertising who are addicted to such games, the distinction between flow and boredom was possible.

\section{From Commercial Games to Serious Games}

In addition to in-game advertising, 'serious games' concerning social issues like healthcare, environment or education, city planning and business simulations concerning business ethics may be employed for enhancing multiple perspectives of individuals and their cultural understanding in developing economies. Likewise, exposing individuals to trade-offs between social responsibility with profitability along with ethical dilemmas/ challenges would facilitate the development of creative solutions that would enhance their competencies. Through understanding and changing priorities or making difficult choices and coping with their consequent results in solo games along with learning interactively by practice through teamwork in multiplayer games, active and optimal learning might be possible (See Bos et al., 2006; Mehalow, 2010). Moreover, the flow experience as a component of online multiplayer games may be explored within the serious games context. For example, we may explore cross-cultural contexts to expand our comprehension of the demarcation between affirmative flow conditions based on perceived challengeskill balance to enhance focusing, strategic planning, learning, remembering and developing skills.

The recent reemergence of non-military serious games (initiated by Microsoft Research-funded games) as a promising frontier of education has introduced the concept of games designed for a serious purpose rather than pure entertainment. Despite the unsuccessful past in the 1980 s and 1990s in the US, collaborative deep learning through mobile learning games still have a lot to offer (Klopfer,2008: 2832 ). If blended with conventional training, serious games applications like simulations may provide another powerful means of knowledge creation, the transfer and sharing across numerous application domains through "crowdsourcing" (Howe, 2008). Considering the positive impact of playing games on reducing stress, enhancing problem-solving, critical thinking, creativity and teamwork along with the increasing ability to interpret visual cues such as maps, graphs and other visual displays of data that are underlined in positive psychology by Csikzenmihalyi, 'educational games' will be employed more in business as well as at universities in the future. Moreover, games may make learning fun and meaningful since they can be designed to bridge real world relevance along with theory with practice as a platform for collaboration.

While new media technologies such as smart phones and tablets are transforming almost all aspects of our lives, advergames are changing business models towards continuous interaction with consumers. Meanwhile, serious games through collaboration and engagement may have affirmative impacts on understanding and solving business dilemmas and even human rights issues through social innovation (McGonigal, 2011; 296-369). By and large, advertising game and serious game designers should consider various issues, such as limiting the time spent in the game, blending face-to-face interaction with online gaming and using cooperative platforms or creative modes as much as possible. Otherwise, immersive use of games may turn into an escape route for killing our valuable time instead of enriching it. That is why parental guidance for children up to 16 years old will be helpful so that in the initial stages of entering into the gaming culture, they will gradually learn the rules and limits of gaming along with the ability to select 
the'right'games. Consequently, raising parental awareness and enhancing digital citizenship and the relevant competencies have to be given high priority (See Livingstone, S. et al., 2011).

On the whole, the researcher hopes that the use of advergames, serious games and other forms of digital games may raise the global quality of life and that sustainability through collaboration will be increasingly preferred in the coming gamer generation. The comfort zone of using popular competitive games that enhance only addiction to immediate gratification without any concern for global or social issues is a waste of potential transforming power of both games and gamers. However, the researcher is afraid that escapist entertainment will continue to overshadow serious games in the near future due to limited resources being invested in the relevant research.

Moreover, the possibility of 'cyberactivism' of alternate reality games on human suffering and the rights of distant others have also been claimed to pave the way to 'false activity' or to 'ethical amnesia' due to compassion fatigue rather than forging an ethical community of human beings, since group identities of 'thick relations' rather than distant strangers often determine our responsible choices (Margalit, 2002; Oliver, 2010; Zizek, 1998). Despite these critical arguments, online games are no longer for isolated nerds and serious games are effective on an educational level of all gamers. Future gaming trends seem to connect virtual game space with real life space; that is why reality will be integrated into games rather than the other way around Thus, when life becomes a game, then escapism becomes the ideal life.

\section{Concluding Remarks for Discussion}

This article has attempted to identify the characteristics of an effective advergame, and to verify their application in practice. After presenting a general analysis of the way in which advergames are supposed to influence consumers' perceptions and buying behavior, the study uses the list of main characteristics in designing advergames in order to verify the existence of these necessary features in 15 active advergames.

Online games in general and advergames in particular have not been an object for studies in the early days of their emergence. With an ever-expanding drive towards consumer culture and commercialization and the preference towards 'advertising-as-entertainment', advergames have become a major genre. Promising areas of empirical research include (1) the relation between the characteristics of the game, the personality of the represented brand, the profile of the targeted audience and the strategic objectives of the marketing campaign; (2) the influence of advergames on the perceptions, attitudes and buying behaviors of both serious gamers and more casual game players and (3) the relation between experiential and material purchasing decision of gamers.

As the Internet becomes more immersive, theories of flow and virtual marketing communication may be further probed if researchers can understand the reasons as to why people immerse themselves in various worlds and how they wish to play and interact there as well as the circumstances that lead to consumer satisfaction through virtual purchases. Indeed, both purchasing and gaming experiences often involve both real and virtual activities. Even solitary virtual experiences may allow more selfinvolvement and immersion through possible flow. To be able to relate effective advergames with brand awareness, further studies may move beyond descriptive cases or exploratory analyses towards controlled experimental designs or experiential sampling methodology (ESM) based on Csikszentmihalyi's flow model to test the ability of advergames in virtual worlds to affect brand recall, attitude changes and purchase intentions and actual purchases in the real world so that comparisons between virtual versus material purchases may be possible and even enhance more conscientious consumers. 
Promising areas of empirical research can be the relation between the characteristics of the game, the personality of the represented brand, the profile of the targeted audience and the strategic objectives of the marketing campaign; or a more detailed investigation of the advergames' influence on the perceptions, attitudes and buying behavior of both serious gamers and game players. The theory of flow and virtual marketing communication may be further probed if researchers can understand the intentions as to why people come to virtual worlds and play and how they wish to interact there by employing qualitative research.

To be able to relate effective advergames with brand awareness, further studies may move beyond descriptive cases or exploratory analyses towards controlled experimental designs or experiential sampling methodology (ESM) based on Csikszentmihalyi's flow model, to test the ability of advergames in the virtual world to affect brand recall, attitude change and purchase intentions and purchase in the real world so that comparison between experiential versus material purchases may be possible. Moreover, the flow experience as a component of online multiplayer serious games in cross-cultural contexts may expand our comprehension of demarcation between affirmative flow conditions based on perceived challengeskill balance enhancing focusing, strategic planning and learning, remembering and developing skills.

On the whole, games can be intrinsically motivating and can adapt to different styles of learners, and different learning styles such as visual, audio and kinesthetic, since games make players engage interactively and often encourage peer-to-peer collaboration. That is why games are gaining significance in both academic and corporate settings where both formative and summative evaluation is relevant as alternative methods. Moreover, there is a commonsense tendency to undermine the value of play in the context of games both at schools and at workplace.
We are not paid to play at work or we study at schools not to have fun but to learn... Many schools and businesses are blaming "addiction" to games. Yet, the future of serious games is no longer gamification. On the contrary, the ordinary life with all its issues becomes the fantasy world of games. Unlike conventional noninteractive non-media based on representation, on-line games are based on simulation; therefore, they are dynamic, interactive and the gamers are not merely spectators but actors, authors and designers who want to understand and change the rules and the systems of the games. That is to say, that the recent mode of thinking, gaming and simulating have more potential to create a framework for scientific and artistic curiosity.

\section{References}

Arkadium (2004). 'New Study Reveals That Women Over 40 Who Play Online Games Spend Far More Time Playing Than Male or Teenage Gamers,' http://www.arkadium.com/aol_study.html [accessed December 2011].

Bakhtin, M. M. (1986). Speech Genres and Other Late Essays, University of Texas Press, Austin.6.

Bannan, K. J. (2002). "Let the Games Begin," http://www.oracle.com/oramag/profit/02 -nov/ [accessed April 2012].

Bos, N. D., Shami, N. S. \& Naab, S. (2006). "A Globalization Simulation to Teach Corporate Social Responsibility: Design Features and Analysis of Student Reasoning," Simulation \& Gaming,Vol. 37, No. 1; March 2006: pp. 56-72.

Cauberge, V. \& De Pelsmacker P. (2010). "Advergames: The Impact of Brand Prominence and Game Repetition on Brand Responses," The Journal of Advertising, Spring 2010; Vol. 39, No. 1: pp.5-18.

Chen, H. (2006). "Flow on the Net: Detecting Web Users' Positive Affects and their Flow States", Computer in Human Behavior,Vol. 22. No. 2: pp. 221-23. 
Chiang, Y.- T., Lin, S. S. J., Cheng, C.- Y. \& Liu, E. Z.- F. (2011). "Exploring online Game Players' Flow Experiences and Positive Affect," The Turkish Online Journal of Educational Technology, January 2011, Vol. 10; Issue. 1: pp. 106-114.

ComScore, "ComScore Finds that "Second Life" Has Rapidly Growing and Global Base of Active Residents," http://www.comscore.com/press/release. asp?press=1425 [accessed April 2012].

Csikszentmihalyi, Mihaly (1991). Flow: The Psychology of Optimal Experience, New York: Harper Perennial.

Fill, C. (2002). Marketing Communications: Contexts, Strategies and Applications, 3rd Edition, FT Prentice Hall.

Hacker, K. \& Dijk, J. (2000). eds. Digital Democracy: Issues of Theory and Practice, Sage pub, U.K: London.

Hartsock, N. (2004). 'Advergames Newly Viable After All these Years,' E-Marketing $I Q$,

http://www.emarketingiq.com/news/140

9 [accessed Dec. 2011].

Hernandez, M. D., Chapa, S., Minor, M. S., Maldonaldo, C. \& Barranzuela, F. (2004). "Hispanic Attitudes toward Advergames: A Proposed Model of their Antecedents," Journal of Interactive Advertising, Vol. 5, No. 1 ,

http://www.jiad.org/vol5/no1/hernandez / [accessed Mar. 2011].

Howe J. (2008). Crowdsourcing. New York: Crown Publishing Group.

Kahneman, D. \& Tversky, A. (eds) (2000). 'Choices, Values and Frames,' N. Y: Cambridge University Press.

Kiani, G. R. (1998). "New Game, New Rules: Will Traditional Mentality Work in the Marketspace?," Management Research News. 21(6) 1-9.

Klopfer, E. (2008). Augmented Learning: Research and Design of Mobile Educational Games, The MIT Press; MA: Cambridge.
Koster, R. (2005). A Theory of Fun for Game Design, Paraglyph Press, AZ: Scottsdale.

Kretchmer, S. B. (2005). 'Changing Views of Commercialization in Digital Games: Ingame Advertising and Advergames as Worlds in Play,' http://www.gamesconference.org/digra20 05 [accessed September 2011].

Lemmens, J. S., Valkenburg, P. M. \& Peter, J. (2009). "Development and Validation of a Game Addiction Scalefor Adolescents," Media Psychology, 12(1), 77-95.

Livingstone, S., Haddon, L., Görzig, A. \& Ólafsson, K., With Members of the EU Kids Online Network (2011). Risks and Safety on the Internet: The Perspective of European Children: full findings and policy implications from the EU Kids Online survey of 9-16 year olds and their parents in 25 countries. LSE; London: EU Kids Online. (See www.eukidsonline.net for Updates on this Ongoing Project in 25 Countries).

Margalit, A. (2002). The Ethics of Memory. Cambridge: Harvard University Press.

Mehalow, C. (2010). "Teaching Sustainable Values through Serious Gaming," In Games that can Change the World, http://www.Triplepundit.com/topc.seriou s-gaming. [accessed Mar. 2011].

McDanial, S. R. (2001). "An Examination of Demographic, Lifestyle and Personality Influences on Consumer Preferences for Participating in Promotional Games," Advances in Consumer Research, 28 (19).

McGonial, J. (2011). Reality is Broken: Why Games Make us Better and How they can Change the World. New York: Penguin Press.

Nelson, M. R. (2002). "Recall of Brand Placements in Computer/Video Games," Journal of Advertising Research, 42(2), pp. 80-92.

Oliver, S. (2010). "Stimulating the Ethical Community: Interactive Game Media and 
Engaging Human Rights Claims," Culture, Theory and Critique, 51, 1, pp. 93-108.

Pearce, J. M., Ainley, M. \& Howard, S. (2004). "The Ebb and Flow of Online Learning," Computer in Human Behavior, Vol. 21: pp.327-63.

Sennott, S. (2004). 'Advertising: The Latest Marketing Trend Makes the Consumer a Player Inside the Commercial,' Newsweek, International Edition.

Youn, S., Lee, M. \& Doyle, K. O. (2003). "Lifestyles of Online Gamers: A Psychographic Approach," [accessed September 2011]. Wardrip_Fruin, Noah \& Montfort, N. eds. (2003). The New Media Reader. The MIT Press; MA: Cambridge.

Yuan, Y., Caulkins, J. P. \& Roehrig S. (1998). "The Relationship between Advertising and Content Provision on the Internet," European Journal of Marketing, 32(7,8) 677-687.

Yüksel, M. (2007). "Küreselleşme Sürecinde Yeni bir İletişim Ortamı," Öneri, 317-26.

Yüksel, M. (2009). 'Reklam Oyunlarının Pazarlama İletişiminde Oynadığı Stratejik Rol,' In Değișen İletişim Ortamında Etkileşimli Pazarlama, Editors, Baruh, L. and Yüksel, Doğan Egmont, Istanbul.

Zizek, S. (2006). How to Read Lacan. London: Granta Books. 